example, after three successive losses caused by an adverse series of noir, the playing of rouge is discontinued and is not resumed until rouge has appeared. It is evident that in this way adverse series of fou or more turns are avoided, but the chance of winnin by' the appearance of rouge before play is resume is lost. With an adverse series of four, therefore, one loss and one gain are avoided, so that the net advantage is zero. With an adverse series of five, two losses and one gain are evaded, so that there is a net gain of one stake. Similar in adverse series of six an seven, the application of the system produces a net gain of two and three stakes. On the other hand, with an adverse series of three, there is a net loss of one stake, because rouge is not played at the next turn when it would have won. As series of three are muc commoner than series of five or more, the player loses more by this system than he would by playing on chance continuously. This is true of all methods in which play is interrupted at a prescribed point of a adverse series. That such methods occasionally suc- ceed is obvious, but

In the attempt to counterbalance the losses caused by zero and refait, most systems make use of th device called "progression," or "massage"-i. e., a systematic increase and decrease of the stakes, according to conditions. The best known and the most seductive of all progressions is the martingale, in which one 5 -franc piece (the unit of play) is staked until a loss occurs, and the stake is doubled after each loss. If the player wins, his net gain is one piece. For example, if he has lost the four first plays, his losses amount to $1+2+4+8=15$ pieces. If he then wins, his gain is 16 pieces, so that his net gain is one piece. Even a very wealthy man cannot play a martingaie beyond eleven turns at roulette or ten at trent et quarante, owing to the limitation imposed by the bank As a series of eleven and more occur daily, the folly of the martingale is obvious. Still more unfavorable for the player is the so-called American progression in which the stake is progressively increased in such a manner that one winning not only repays preceding losses, but gives a net gain of one piece for each play. The progression is therefore 1-3-7-31, etc. This can be played for only ten turns at roulette or nine at trente et quarante.

The employment of all such progressions means certain ruin. In many' cases the player may win, owing to the non occurrence of adverse series of nine or more, but one such series will at least wipe out all preceding winnings. If the progression is a rapid one the player will win comparatively often and lose a great deal in case of disaster; if it is a slow one, he will win less often and a smaller sum, and his losses will also increase less rapidly. In the long run progressions offer no advantage over playing with un. changed stakes.

A fuller analysis of these systems is given in G. Walter's recently published (German) book, "Rules and Systems of Play at Monte Carlo," the author of which contributes to Ueber Land und Meer, the article from which this account is translated.

\title{
What Constitutes Superiority in an Airship
}

\section{An Analysis of Existing Types}

\section{By Commandant Paul Renard}

The question has been much discussed as to what type has the most noteworthy qualities among the numerous devices which are to-day carrying men through the air. Some are partisans of the aeroplane others of the dirigible, and these two camps are always in rivalry, sometimes in open enmity, so that unanimity is far from prevailing.

In aviation there are monoplane and biplane enthusiasts, those who prefer aeroplanes without a tail, such as the Wrights' machines, ${ }^{1}$ or with a tail, like all the others. In aerostation, or ballooning, some contend for the flexible type like the "Ville de Paris," others for the semi-rigid type like the "Republique, and lastly, others who vaunt the merits of the rigid type, like the "Zeppelin."

How can anyone know where to stand in the face of all these opinions? From a technical point of view, excellent arguments can be found in favor of each of the present types of air-ships as well as for those which may be later devised; specialists can discuss these questions indefinitely. Although as far as I am concerned I have a well-established opinion on this point, it is not from the theoretical standpoint that I wish to express myself to-day, but without wishing to pass judgment it seems to me worth while to at least indicate the considerations on which such a judgment should be based. In a word, I should like to determine here what from a practical point of view at the qualities which can be demanded in an air-shij and from among these qualities to choose those which are of the greatest importance and which as a consequence should preferably serve as a criterion in passing judgment on a structure of a new kind.

According to the point of view very different sorts of performances if I may use such an expression, may be expected of an air-ship. You may, for example, wish to rise as high as possible in the air, and the wish to rise as high as possible in the arr, and the evidently a quality to be considered. It is not enough merely to rise, however, but it is also necessary to merely to rise, however, but it is also necessary to
stay there. The period during which the air-ship shall remain suspended in the air without touchin the ground, therefore, is also one of the elements of interest in the question. Another phase of the question is that any engine
of locomotion must be able to cover distances; the distance which separates the point of departure from the finishing point is therefore one of the essential characteristics of a voyage. In fact one might be tempted to say that the best air-ship is the one that can travel the greatest distance in a single flight before touching the earth.

Finally, it is not only necessary that a certain given distance shall be covered, but it must take the shortest possible time to accomplish it. In other words, speed is the most highly valued quality at the present day. In all types of locomotion, whether by bicycle, automobile, railroad trains, steamboat, or motor boat it seems that the principal aim is speed, always speed, and still more speed. This search fo acceleration in means of transportation is one of th characteristics of our epoch; and it is not to be wondered at, for although all space is open to us, still our time is parsimoniously dealt out to us, and the

* Translated for the Smithsonian Institution's Annual Re port from Revue des Deux Mondes, vol. 54, November 1st,
1009 , pp. 181-199.
1 The Wright aeroplane is now provided with a tail, or rea

horizontal rudder.-En. best way we can use it is to carefully economize it by the use

Aerial navigation does not escape from this gexeral aw of locomotion. Speed is therefore one of the im law of locomotion. Speed is therefore one of the im-
portant elements in the measurement of the value of portant elements in the measurement of the value of
an air-ship. But a distinction must here be made, for there are two kinds of speeds to be considered, termed absolute speed, and individual speed. The absolute or effective speed is the one commonly considered. It is the speed measured with regard to the ground over which the air-ship is passing. If a dirigible starts from Paris at 8 in the morning and at 11 o'clock is above Auxerre, the distance between the two cities being 150 kilometers as the crow flies we would say that its absolute velocity had been on the average 50 kilometers an hour. This absolute speed is the one of practical interest. It is the plain fact, all modifying circumstances being removed from the calculation.

From the point of view of merit in a device, however, it is precisely these modifying circumstances that should be considered. The effective velocity re sults from the combination of two other velocitiea, namely, the individual velocity of the vehicle, whic will be defined shortly, and the velocity of the wind. Everyone knows what the velocity of the wind means. As for the individual velocity of an air-ship, its definition is very simple; it is the velocity whic the air-ship could attain if there were no wind, or again, it is the velocity in calm air, or finally, it velocity in comparison with the ambient air, con idering this to be at rest.

Of these two elements, the combination of which determines the absolute velocity, one, the individual velocity, depends on the construction of the air-ship; and the efforts of all aeronautic engineers are directe toward giving this as great a value as possible; the other element the velocity of the wind, is entirely beyond us and we must submit to it, whatever it is. But according to direction and velocity of the wind, it is necessary to have very different individual velocities to obtain a determined effective velocity.

If for example, on the day when our dirigible trav eled from Paris to Auxerre in three hours, the wind had blown exactly in the desired direction with a velocity of 50 kilometers an hour, the wind alone would have been sufficient to accomplish the voyage in the time given without any intervention of the individual velocity. The aeronaut could have stopped his motor and thus would have made the journey at little cost. The effective speed would be the same as the velocity of the wind, the individual speed zero;
the wind would have done all and the machine nothing.

If the wind, however, although blowing in the proper direction from Paris to Auxerre, had had a velocity of only 30 kilometers an hour the aeronaut, if he were contented with allowing himself to be carried by the wind, would have taken five hours to make the journe; instead of three. To attain the previous speed of 50 kilometers per hour he would have to add to the velocity of the wind the 20 kilometers lacking, and this difference would be nothing else but his individua speed. In such a case we should say that the velocity of the wind had been 30 kilometers an hour, the in dividual velocity 20 , and the effective or absolute velocity 50 kilometers per hour. Instead of doing all greater part and the motor the rest. the work as before, the wind had only done the
If the velocity of the wind had been but 10 kilometers, the motor this time would have had to add not 20 kilometers but 40 . In this case the motor would have deserved the principal credit for the voyage, and the wind would have furnished only a slight supplementary velocity.

Let us suppose now that the air is absolutely calm, that is, the velocity of the wind is zero. The motor alone can be counted on here, and it is due to it that the speed of 50 kilometers an hour is attained. The effective velocity will be equal to the individual velocity, and the motor will have done all and the wind nothing.

Finally, if the wind, with a velocity of 20 kilometers an hour is blowing not in such a direction as to be astern from Paris to Auxerre, but in the opposite direction the motor will be required to furnish an individual speed of 80 kilometers an hour. The first 30 are used up merely in compensating for the unfavorable effects of the wind, the other 50 alone being effective. This time the motor has not only done everything, as in calm air, but it has done more, for in addition to the absolute velocity it has had to furnish a surplus of individual velocity to counterbalance the hindering effect of the wind.

In a word, in order to attain the same practical result as before, that is, an absolute velocity of 50 kilometers an hour, the motor should be capable of giving to the air-ship an individual velocity of 0,20 , 40,50 , or 80 kilometers an hour.

We have considered here only the simplest casewhen the wind blows in the direction of the place to be reached or in exactly the opposite direction. This is almost never the case in practice, so that it becomes necessary in each case to determine what the individual velocity must be to attain a certain absolute speecl. The problem is now a little more complicated, but the conclusions are the same, and the individual velocity is necessarily sometimes less, sometimes more, than the absolute velocity, and at times the two may even be equal. To sum up, all that may be said is that the wind can be either a help or a hindrance to the progress of air-ships, and in exceptional cases neither obstructs nor is favorable to their evolutions.

By those with a different point of view, it may finally be asked if there is not opportunity to measure the value of an air-ship by the amount of useful weight carried, in personnel or in material. The power of transporting is certainly one of the qualities sought for in certain vehicles.

All the qualities which we have passed in reviewaltitude, duration of voyage, distance covered, velocity, power of transportation-have the common characteristic that they may be measured exactly, their value can be expressed in precise figures, and thus they furnish a fixed mathematical standard of comparison between different types of air machines, for they are based on rigorous observations, and questions of sentiment have not intervened. For instance, if the altitude attained should be taken as the criterion of the value of a dirigible, the one that has ascended to a height of 1,500 meters is incontestibly superior to one that has only attained a height of 1,200 meters. If it is a matter of distance covered, the one which in a single flight has traveled 800 kilometers is superior to one which has only covered 600 . That much is perfectly clear.

There are other qualities, however, less exact in thelr nature, which nevertheless are not negligible, such as 
security, comfort, and pleasure of voyages.

I do not care to enter into a detailed examination of these phases of the subject, partly because they can not be exactly valued, and further because they are readily attained by devices of secondary importance Thus by the use of flexible cushions and backs with head rests the traveler's comfort is easily increased. These are questions to be referred to the skill of an upholsterer and not to an engineer.

There is, however, one property that is highly im portant for safety and comfort in a voyage-the stability of the vehicle. This stability is obtained by mechanism of a technical nature; it is often ver difficult to obtain and therefore should be considered in connection with the more exact qualities first dis cussed. In a given vehicle, stability can be interpreted in several ways. The center of gravity of the apparatus can describe a very regular trajectory, but the vehicle may nevertheless be exceedingly unstable; it may go through oscillatory movements which ar highly uncomfortable and occasionally dangerous These movements have been given different names according to the direction they follow. When they are in a horizontal plane they are said to be zigzas are in a horizontal plane they are said to be zigzas movements or yawing. If it is a question of vertical
movement, it may be of two sorts-in a longitudinal direction it is called pitching, and if in a traverse direction it is rolling.

Although displacements of this kind do not affect the trajectory of the center of gravity, and conse. quently can not prevent the vehicle from following its course, they are none the less disagreeable, especially if several of them are combined. Stability of direction, longitudinal stability, and transverse stabilty, which will enable us to avoid, respectively, yawing, pitching, and rolling, are therefore qualities highly desirable.

There is a fourth sort of stability that is a special quality of airships. This is stabnlity of altitude. Land vehicles are forced to keep to the level of the ground on which they rest. Aquatic carriers float on the surface of the water: air-ships, on the contrary, and with them must be classed submarines, are sub. and with them must be classed submarines, are sub.
merged in a fluid and can ascend and descend through the gaseous or liquid mass. When the air-ship re. mains at the altitude chosen by the pilot, or when it mounts or descends at his will, it is said to have stability of altitude. It does not have this quality when its vertical movements are involuntary and beyond the control of the aeronaut.

II.

We have thus completed the enumeration of the qualities which an air-ship may possess. The question is not to choose from among them those most important in determining the value of the conveyance. But before making this choice it is indispensable to know from what point of view it is to be made. One may inquire as to which of these qualities is the most difficult to obtain. If the technical standing of engi. neers were to be determined that would be the cours to pursue, and we would proclaim the superiority of the constructor who had endowed his machine with the qualities which are the hardest to attain. But is not a question of awarding prizes to engineers. We want to know what air-ships have the greatest practical advantages. In making our choice of qual ities we shall not demand, therefore, those most difficult of attainment, but those most desirable in them selves. We can afterward inquire if the most desiraselves. We can afterward inquire if the most desira-
ble qualities are more or less difficult to realize; this will be merely an accessory matter

We are therefore called upon to pass judgment upon the practical advantages in types of air-ships. The first consideration is not to lose sight of the conditions under which by definition itself an air-ship is operated, conditions different from those which a boat or a railway train meets; no one can justly make an estimate of such dissimilar devices without recos. nizing the fundamental condition:s of their utilization nizing the fundamental conditiors of their utilization;
that is, the nature of the supporting medium in which that is, the nature of the supporting
they move, the earth, water, or air

Locomotion on land brings into touch all the habitable places on the earth except those separated from one another by expanses of water impossible to bridge. But with this advantage there is still an element of great disadvantage. To attain on land perfect condigreat disadvantage. To attain on land perfect condi-
tions for speed and carrying power, it has not been tions for speed and carrying power, it has not been enough merely to train animals or create powerful
and ingerious machines. These achievements would not have counted for much unless the route had been prepared by the construction of roadways, involving an enormous amount of labor and money. Without highways and railways, automobiles and locomotives would be powerless. This is so true at the present day that the importance and the perfection of the wavs of communication are considered the principal cri. teria of material civilization, and where these means are lacking we are no further advanced than were those of the days of Joshua.

A water transportation line, and herein lies its in. feriority, only admits of the joining together of a very limited number of places, those along the shores of seas or along navigable streams. There is, however, the enormous advantage of not requiring a preliminary preparation of roadways. To travel by water with all the perfection possible to obtain, it is only necessary to have good ships. The sea has at $8: 1$ times been the chief means of communication between the various countries of the globe; all the ocean shores have been fairly well known for a long period, while there have remained immense tracts of country unexplored in the interior of the continents. If, to venture an hypothesis, there existed in the center of Africa, or in the midst of the deserts of Asia, an unknown but populous city, the center of a flourishing civilization, the explorers who had discovered it could tell of its marvels on their return, but this newly discovered city would still remain apart from genera civilization simply because it was not connected with other countries by perfected ways of communication. If, on the contrary, there should be discovered in the

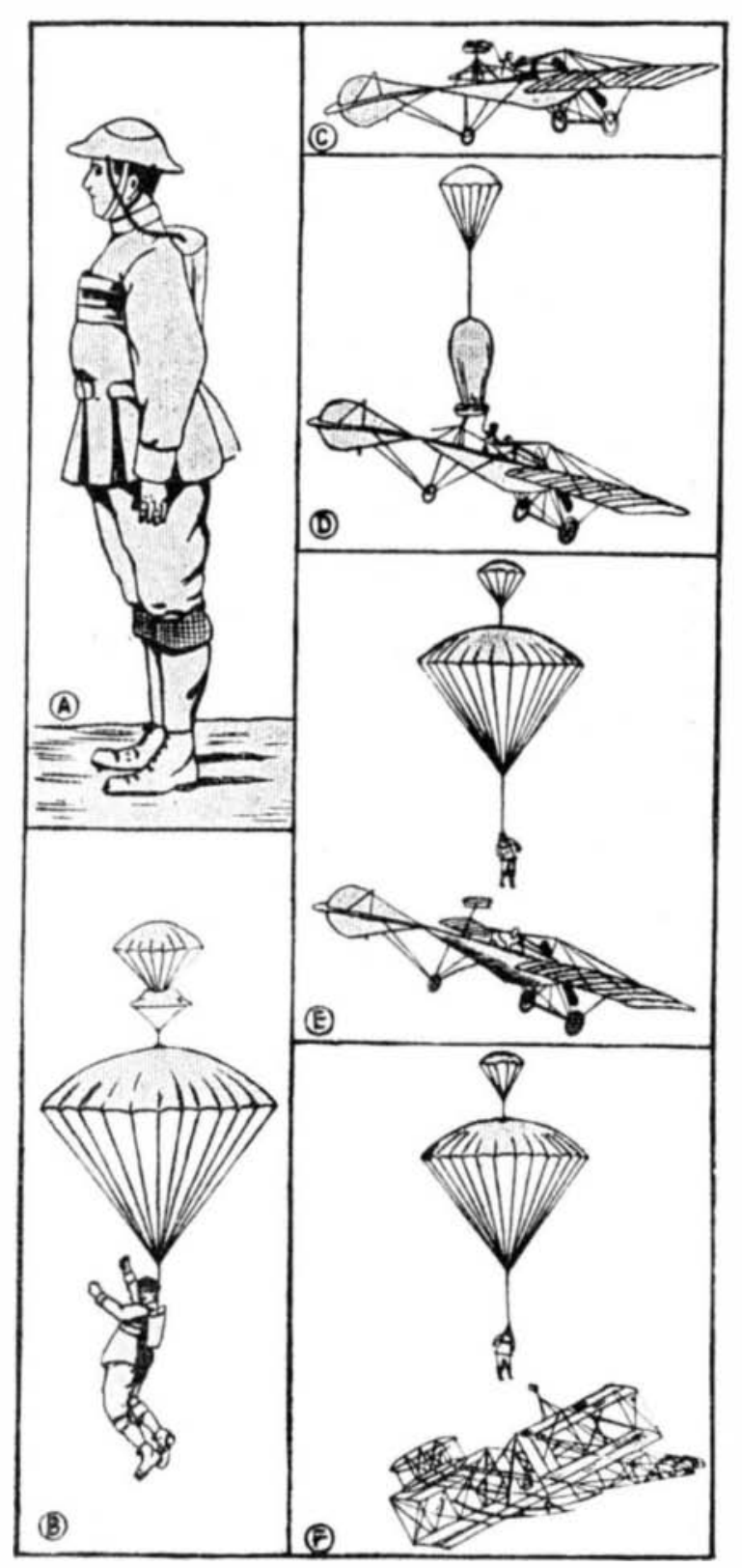

-Aviator, cquipped with the apparatus. B. The two
parachutes opened. C. D. E. E. Three phases in the fall of
a monoplane Fi.-Aviator escaping from a falling bi-
plane, having a divided upper plane.

A LIFE PRESERVER FOR AVIATORS.

olitudes of the Pacific an islet, in itself of little im portance, it could be brought into direct communica tion with New York. Marseilles, and Sidney, an? ente immediately into the circle of mundane affairs.

Aerial navigation combines the advantages of its older sisters and is free from their inconveniences. It can connect Paris and Rio de Janeiro as wal! a Madrid and St. Petersburg. It no more requires the preliminary construction of roads of communication than does maritime transportation. It creates dire? bonds of communication without intermediary agen cies, and to utilize it, it is only necessary to have appropriate vehicles. Thanks to this means, all point cn the globe may enjoy the privilege which has hith. erto been reserved to the shores of the sea, and in a few years the atmosphere will certainly be the great nedium for bringing people together just as the ocean las been for a long time in its more limited and less perfect fashion.

\section{Recent Turbine Efficiencies}

E. D. Dreyfus read a paper lately before the Engineers' Society of Pennsylvania on recent turbin efficiencies. He stated that, while 1,800 r.p.m. used to be the limit of rotative speed for turbo-generators of more than $500 \mathrm{kw}$., improvement in the electrica portion of the equipment now makes it possible to operate turbines of $2,500 \mathrm{kw}$. at 3,600 r.p.m., and.It is expected that soon turbines of $4,000 \mathrm{kw}$. will be driven at that speed. The symmetrical form of the Westinghouse double-flow turbine, greatly assists in carrying out these improvements, and along with improved construction an economy of 3 to 5 per cent. has resulted, in both large and small sizes, due to altered distribution of steam and temperature and to better blade lengths. One of the Westinghouse straight double-flow turbines of $10,000 \mathrm{kw}$. capacity, installed at the City Electric Co., San Francisco, has developed $1 \mathrm{kw}$-hour with $13.88 \mathrm{lbs}$. steam of $175 \mathrm{lbs}$. pressure, 80 to 90 deg. F. superheat and 28 in. vacuum. The best result previously got from a reciprocating engine under those conditions was about $17 \mathrm{lbs}$. steam.

\section{A Life Preserver for Aviators}

PIRIo has invented a life-saving apparatus for aviators, whioh is described and illustrated in a recent issue of L'Aérophile. The apparatus comprises a large parachute, which is folded and inclosed in a light case attached to the back of the aviator, and a small parachute, attached to the aviator's helmet, and folded in such a manner that it will open automatically in case of fall. The cord of the small parachute is fastened to the top of the large one, which is drawn out of its case by the traction of the cord, and then automatically unfolds and carries the aviator slowly and safely to earth, free from the swiftly falling aeroplane, as the illustrations show.

The large parachute is made of very thin silk, and has a diameter of 33 feet, and an effective area of 770 square feet. It has 30 gores, and as many converging cords, 33 feet long, attached at their junction by a stouter cord to the aviator's body. The folded parachute is packed in a case measuring $12 \times 12 \times 2$ inches, which weighs, with its contents and attachments, only 13 pounds. Two auxiliary parachutes, $31 / 3$ and $161 / 2$ feet in diameter, are provided. When the apparatus is used with a biplane, the upper plane must be divided, to allow the aviator to escape.

\section{Germs at Different Air Elevations}

AT a recent meeting of the French Agricultural Society, M. G. Bonnier gave an account of his experiments relating to germs of various kinds which are found in the air, either fungus spores or bacteria. These are contained in the air in varying amounts according to the height of the air or the locality. He finds that the number and the nature of these germs vary remarkably with the different places from which they are taken. A special apparatus was designed for collecting and observing the germs. He verifies the exactness of the already formed conclusion as to the decrease in the number of germs as we proceed higher in the air. It was also affirmed that there were numerous fungus spores to be found even at great heights in the atmosphere, and M. Bonnier's. results agree with this, as he also found many of tro..1. This point is an interesting one as it concerns the fermentations which are now recognized to play so important a part in agriculture.

\section{Evaporation of Wine}

IN experiments on evaporation of wine carried out at the Auxerre laboratory in France, the wine was exposed to the air in a flat dish in a one-inch layer. The results after three days, compared with the composition at the start, are given. The amount of alcohol was at first 8.05 per cent, and it fell to 1.75 per cent after three days. As to the acidity, this was slightly increased, or 5.18 compared to 4.39 . The dry extract from the wine rose from 17.4 to 20.3 per cent. extract from the wine rose from 17.4 to 20.3 per cent.
By evaporating, the alcohol almost all disappears and the other elements are concentrated. The wine exposed in this way loses its alcohol by evaporation before any of the germs commence to act upon it.

\section{TABLE OF CONTENTS}

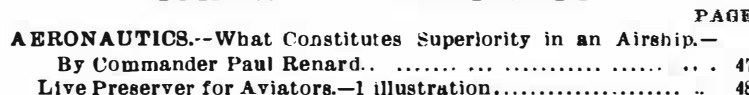

II. BACT ERIOLOG Y.-Germs at Different Air Elevations............

III. ELECTRICITY.-Multiplex Telephony and Telegraphy.-III.-By 7. ENGINRERING.-Power Plant Betterment.-By H. H. Iunt... Oil-driven Boats for Canadian Lakes and Canals.-By Our Parie

v. MISCELLANEOUS.-The Prevention and Control of Fires

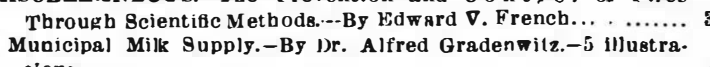

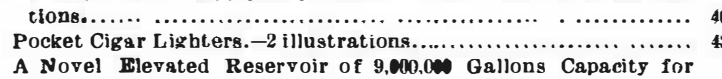

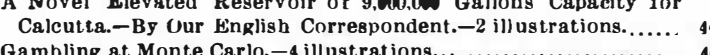

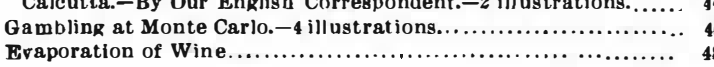
VI. PHYBICS.-Radiant Energy and Matter.-VI....................

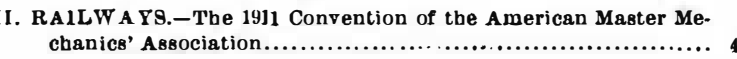

